$\begin{array}{lrrrr}\begin{array}{l}\text { FOUNDATIONS } \\ \text { Vol. } 37\end{array} & \text { OF COMPUTING } & \text { AND } & \text { DECISION } & \text { SCIENCES } \\ \text { (2012) } & & \text { No. } 1\end{array}$

DOI: $10.2478 / \mathrm{v} 10209-011-0001-1$

\title{
BEHAVIORAL MULTI-CRITERIA DECISION ANALYSIS: FURTHER ELABORATIONS ON THE TODIM METHOD
}

\author{
Luiz Flavio AUTRAN MONTEIRO GOMES* \\ Xavier Ignacio GONZÁLEZ
}

\begin{abstract}
This short communication reviews the role of the TODIM method within behavioral decision theory and presents its genesis. Two important aspects of the method such as generalizing that method towards cumulative prospect theory and the choice of a reference point are further clarified.
\end{abstract}

Keywords. Cumulative prospect theory, decisions under risk, multi-attribute decision making.

\section{Introduction}

Behavioral decision theory is considered to have formally begun with Ward Edwards 1954 Psychological Bulletin article [3], [16]. More recently, Eisenführ, Weber, and Langer have established behavioral decision theory as "The approach of reflecting on axiomatic frameworks in the domain of descriptive theories (...) geared towards our goal of decision support". These three authors also point out that the cumulative prospect theory by Tversky and Kahneman [21] is "currently the most prominent descriptive decision theory under uncertainty" [4].

The first articles presenting the TODIM method [6], [7] came out in the same year when Tversky and Kahneman published their extension of Prospect Theory [11] to Cumulative Prospect Theory [21]. According to Eisenführ; Weber; and Langer [4], "the original Prospect Theory (OPT) from 1979 is only of historical importance today. However, to prevent possible misunderstandings, the cumulative version of Prospect Theory is commonly referred to as CPT."

${ }^{*}$ Ibmec/RJ, Av. Presidente Wilson, No. 118, Room 1110, CEP: 20030-020, Rio de Janeiro, Brazil, e-mail: autran@ibmecrj.br

** School of Engineering, University of Buenos Aires, Av. Las Heras 2414 Piso $1^{\circ}$. Departamento C1127AAR, Buenos Aires, Argentina, email: xavierign@gmail.com 
The genesis of the TODIM method lays in early research by Salminen [17], [18], [19]. This author further extended the work of Korhonen; Moskowitz; and Wallenius on linear prospect theory within the context of multiple criteria decision problems [13]. The TODIM method, however, departs from these early writings as it is founded on the original, nonlinear prospect theory.

The purpose of this short communication is to further elaborate on two important aspects of TODIM that deserve to be clarified. That elaboration is then presented under the form of two comments: (i) generalizing TODIM towards cumulative prospect theory; and (ii) choice of a reference point. This communication closes by outlining directions for future research.

\section{Two Comments on the Analytical Formulation of the TODIM Method}

\subsection{Generalizing the TODIM Method towards Cumulative Prospect Theory}

Mathematical expressions (1), (2) and (3) constitute the modeling underlying the use of the TODIM multicriteria decision aiding method [5], [6], [7], [8], [8], [15], [20]:

$$
\begin{gathered}
\delta\left(A_{i}, A_{j}\right)=\sum_{c=1}^{m} \Phi_{c}\left(A_{i}, A_{j}\right) \\
\Phi_{c}\left(A_{i}, A_{j}\right)= \begin{cases}\sqrt{\frac{w_{r c}\left(P_{i c}-P_{j c}\right)}{\sum_{c=1}^{m} w_{r c}}} & \text { if }\left(P_{i c}-P_{j c}\right)>0 \\
-\frac{1}{\theta} \sqrt{\frac{\left(\sum_{c=1}^{m} w_{r c}\right)\left(P_{j c}-P_{i c}\right)}{w_{r c}}} & \text { if }\left(P_{i c}-P_{j c}\right)=0\end{cases} \\
\xi_{i}=\frac{\sum_{j=1}^{n} \delta\left(P_{i c}-P_{j c}\right)<0}{\max \sum_{j=1}^{n} \delta\left(A_{i}, A_{j}\right)-\min \sum_{j=1}^{n} \delta\left(A_{i}, A_{j}\right)}
\end{gathered}
$$

where:

$\delta\left(A_{i}, A_{j}\right)=$ measurement of dominance of alternative $A_{i}$ over alternative $A_{j}$; $\mathrm{m}=$ the number of criteria; 
$\mathrm{c}=\mathrm{a}$ generic criterion;

$\mathrm{w}_{\mathrm{rc}}=$ trade-off rate between any criterion taken as a reference criterion $\mathrm{r}$ and any other, generic criterion c;

$\mathrm{P}_{\mathrm{ic}}, \mathrm{P}_{\mathrm{jc}}=$ evaluations of alternatives $\mathrm{i}$ and $\mathrm{j}$ with respect to criterion $\mathrm{c}$;

$\theta=$ attenuation factor of the losses; different choices of $\theta$ lead to different shapes of the prospect theoretical value function in the negative quadrant;

$\Phi_{\mathrm{c}}\left(\mathrm{A}_{\mathrm{i}}, \mathrm{A}_{\mathrm{j}}\right)=$ contribution of criterion $\mathrm{c}$ to function $\delta\left(\mathrm{A}_{\mathrm{i}}, \mathrm{A}_{\mathrm{j}}\right)$, when comparing alternatives $A_{i}$ and $A_{j}$;

$\xi_{\mathrm{i}}=$ normalized global performance of alternative $\mathrm{A}_{\mathrm{i}}$, when compared against all other alternatives.

The function $\Phi_{\mathrm{c}}$ reproduces the Prospect Theory value function introduced by Kahneman and Tversky in 1979 [11] and replicates the most relevant shape characteristics. First, it fulfills the concavity for positive outcomes (convexity for negative outcomes) and second, it enlarges the perception of negative values for losses than positive values for gains, both value functions are steeper for negative outcomes than for positive ones. It is worth observing that, together with the value function, these two authors introduced the weighting function that measures the subjective perception of probabilities. As TODIM is a deterministic method, only the value function is extended.

Each shape characteristic of the value function models psychological processes: The concavity for gains describes a risk aversion attitude, the convexity describes a risk seeking attitude; secondly, the assumption that losses carry more weight than gains is represented by a steeper negative function side.

Different kinds of decision makers can be understood in terms of their risk and loss attitude. Although the TODIM method does not deal with risk directly, the way the decision maker evaluates the outcomes of any decision can be expressed by their risk attitude: for instance, a cautious decision maker will under-valuate a superior result more than a braver one. Apart from parameter $\theta$, the attenuation factor of the losses, function $\Phi$ does not offer other parameters to delineate the behavior of diverse decision makers, therefore a generic formulation is proposed.

When introducing the CPT in [21], Tversky \& Kahneman define the subjective value $\mathrm{v}$ of an outcome $\mathrm{x}$, as a two-part power function of the form:

$$
v=\left\{\begin{array}{ccc}
x^{\alpha} & \text { if } & x \geq 0 \\
(-\lambda)(-x)^{\beta} & \text { if } & x<0
\end{array}\right.
$$

In (4) $\alpha$ quantifies the curvature of the subjective value function for gains, $\beta$ does for losses, and the parameter $\lambda$ quantifies the loss aversion. For $\alpha, \beta<1$, the value function exhibits risk aversion over gains and risk seeking over losses. Furthermore, if $\lambda$, the lossaversion coefficient, is greater than one, individuals are more sensitive to losses than gains. In [20], using non-linear regression the values of the parameter were estimated, $\alpha=\beta=0.88$ and $\lambda=2.25$. Other estimations from experimental data were conducted in [1] and [10].

Function $\Phi_{\mathrm{c}}$ can be expressed as an instance of CPT value function having $\alpha=0.5, \lambda=1$ / $\theta$ and (5), 


$$
x=\left\{\begin{array}{cll}
\frac{w_{r c}\left(P_{i c}-P_{j c}\right)}{\sum_{c=1}^{m} w_{r c}} & \text { if } \quad\left(P_{i c}-P_{j c}\right) \geq 0 \\
\frac{\left(\sum_{c=1}^{m} w_{r c}\right)\left(P_{j c}-P_{i c}\right)}{w_{r c}} & \text { if } \quad\left(P_{i c}-P_{j c}\right)<0
\end{array}\right.
$$

However, a more general parametric form of the function $\Phi_{\mathrm{c}}$ is introduced in (6)

$$
\Phi_{c}\left(A_{i}, A_{j}\right)=\left\{\begin{array}{cl}
\left(\frac{w_{r c}\left(P_{i c}-P_{j c}\right)}{\sum_{c=1}^{m} w_{r c}}\right)^{\alpha} & \text { if }\left(P_{i c}-P_{j c}\right)>0 \\
(-\lambda)\left(\frac{\left(\sum_{c=1}^{m} w_{r c}\right)\left(P_{j c}-P_{i c}\right)}{w_{r c}}\right)^{\alpha} & \text { if }\left(P_{i c}-P_{j c}\right)=0
\end{array}\right.
$$

This re-definition of function $\Phi_{c}$ will permit TODIM users to simulate their decisions among different set of parameter values tied to each decision maker physiologic profile and contextual conditions.

\subsection{Choice of a Reference Point}

In Prospect Theory the decision maker evaluates changes relative to a reference point perceived as neutral rather than using final wealth as an argument in his value function [11], [12]. For this reason it is important to clearly specify what that reference point is in any Prospect Theory-based decision aiding method such as TODIM. There are indeed two alternative ways to accomplish that when using TODIM:

(I) The reference point has as its coordinates (zero gain, zero loss) elements for every criterion. This is the notion of reference point used in [5], [6], [7], [8], [9], [15], [20].

(II) The reference point is taken as the status quo [3]. However, it may be quite difficult to identify what the status quo is for a given decision context. Salminen [18] pointed out the difficulty related to test the use of prospect theory in explaining choice behavior given that the reference point is indeed subjective and unknown. This suggests that alternative (I) is indeed the most 
promising way to specify the reference point for any given problem in the absence of additional information.

\section{Directions for Future Research}

We foresee three major research directions to be pursued:

(I) For a number of relevant decision problems evaluate the risk aversion of the decision makers by making the $\alpha$ and $\lambda$ values vary as parameters of the TODIM method;

(II) Exploring the interrelationships between the cumulative prospect theory-based TODIM method and the Choquet integral [2], [21]; and

(III) For situations where input data on preferences are either entirely unavailable or only partially available approach the ranking problem can be treated as in inverse problem and then approached by Monte Carlo simulation; this will lead to a SMAA-P method along the lines conceived by Lahdelma and Salminen [14].

\section{Acknowledgement}

Research leading to this article was partially supported by the National Council for Scientific and Technological Development (CNPq) of Brazil through Process No. 310603/2009-9.

\section{References}

[1] Camerer C.F. and Ho T.-H., Violations of the Betweenness Axiom and Nonlinearity in Probability, Journal of Risk and Uncertainty, 8, 1994, 167-196.

[2] Choquet G., Theory of capacities, Annales de l' Institut Fourier, 5, 1953, 131-295.

[3] Edwards W., The Theory of Decision Making. Psychological Bulletin, 41, 1954, 380 417.

[4] Eisenführ F., Weber M. and Langer T., Rational Decision Making, Springer Verlag, Berlin, 2010.

[5] Fa-dong C., Xiao Z., Feng K., Zhi-ping F. and Xi C., A Method for Interval Multiple Attribute Decision Making With Loss Aversion, 2010 International Conference of Information Science and Management Engineering, 2010.

[6] Gomes L.F.A.M. and Lima M.M.P.P., TODIM: Basic and Application to Multicriteria Ranking of Projects with Environmental Impacts, Foundations of Computing and Decision Sciences, 16, 1992a, 113-127. 
[7] Gomes L.F.A.M. and Lima M.M.P.P., From Modelling Individual Preferences to Multicriteria Ranking of Discrete Alternatives: A Look at Prospect Theory and the Additive Difference Model, Foundations of Computing and Decision Sciences, 17 (3), 1992b, 171-184.

[8] Gomes L.F.A.M. and Rangel L.A.D., An Application of the TODIM Method to the Multicriteria Rental Evaluation of Residential Properties, European Journal of Operational Research, 193, 2009, 204-211.

[9] Gomes L.F.A.M., Rangel L.A.D. and Maranhão F.J.C., Multicriteria Analysis of Natural Gas Destination in Brazil: An application of the TODIM Method, Mathematical and Computer Modelling, 50, 2009, 92-100.

[10] Gonzalez R. and Wu. G., On the Shape of the Probability Weighting Function, Cognitive Psychology, 38, 1999, 129-166.

[11] Kahneman D. and Tversky A., An Analysis of Decision Under Risk, Econometrica, Vol. 47, No. 2, March, 1979, 263-292.

[12] Kahneman D. and Tversky A., Choice, Values, and Frames, Cambridge University Press, Cambridge, 2000.

[13] Korhonen P., Moskowitz H. and Wallenius J., Choice Behavior in Interactive Multiple Criteria Decision-Making, Annals of Operations Research, 23, 1990, 161-179.

[14] Lahdelma R. and Salminen P., Prospect Theory and Stochastic Multicriteria Acceptability Analysis (SMAA), Omega, 37, 2009, 961-971.

[15] Moshkovich H.M., Gomes L.F.A.M. and Mechitov A.I., An Integrated Multicriteria Decision-Making Approach to Real Estate Evaluation: Case of the TODIM Method, Pesquisa Operacional, 31 (1), 2011, 3-20.

[16]Phillips L.D. and von Winterfeldt D., Reflections on the Contributions of Ward Edwards to Decsion Analysis and Behavioral Research. In: Edwards W., Miles Jr. R. and von Winterfeldt D. (eds), Advances in Decision Analysis From Foundations to Applications, Cambridge University Press, Cambridge, 2007, 71-80.

[17] Salminen P., Generalizing Prospect Theory to the Multiple Criteria Decision-Making Context, Unpublished paper, 07-07-1991, University of Jyväskylä, 1991.

[18] Salminen P., Descriptive and Prescriptive Modelling of Preferences within a Discrete Alternative Multiple Criteria Decision Framework, Jyväskylä Studies in Computer Science, Economics and Statistics, 19, University of Jyväskylä, 1992.

[19] Salminen P., Solving the Discrete Multiple Criteria Problem Using Linear Prospect Theory, European Journal of Operational Research, 72, 1994, 146-154.

[20] Trotta L.T.F., Nobre F.F. and Gomes L.F.A.M., Multi-Criteria Decision Making - An Approach to Setting Priorities in Health Care, Statistics in Medicine, 18, 1999, 33453354.

[21] Tversky A. and Kahneman D., Advances in Prospect Theory, Cumulative Representation of Uncertainty, Journal of Risk and Uncertainty, 5, 1992, 297-323.

Received July, 2011 